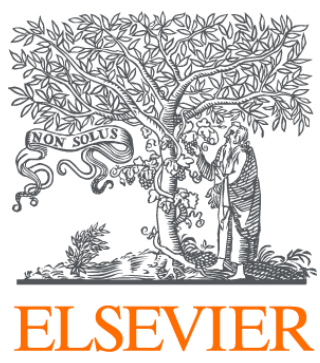

Since January 2020 Elsevier has created a COVID-19 resource centre with free information in English and Mandarin on the novel coronavirus COVID-

19. The COVID-19 resource centre is hosted on Elsevier Connect, the company's public news and information website.

Elsevier hereby grants permission to make all its COVID-19-related research that is available on the COVID-19 resource centre - including this research content - immediately available in PubMed Central and other publicly funded repositories, such as the WHO COVID database with rights for unrestricted research re-use and analyses in any form or by any means with acknowledgement of the original source. These permissions are granted for free by Elsevier for as long as the COVID-19 resource centre remains active. 


\title{
Separation and isolation methods for analysis of the active principles of Sho-saiko-to (SST) oriental medicine
}

\author{
Nobuhiro Ohtake $^{\mathrm{a}, *}$, Yoichiro Nakai ${ }^{\mathrm{b}}$, Masahiro Yamamoto $^{\mathrm{a}}$, Iwao Sakakibara ${ }^{\mathrm{b}}$, \\ Shuichi Takeda ${ }^{a}$, Sakae Amagaya ${ }^{b}$, Masaki Aburada ${ }^{c}$ \\ ${ }^{a}$ Medicinal Evaluation Laboratories, Tsumura Research Institute, Tsumura \& Co., 3586 Yoshiwara, Ami-machi, \\ Inashiki-gun, Ibaraki 300-1192, Japan \\ ${ }^{\mathrm{b}}$ Pharmacognosy and Medicical Resources Laboratories, Tsumura Research Institute, \\ Tsumura \& Co., Ibaraki, Japan \\ ${ }^{\mathrm{c}}$ Tsumura Research Institute, Tsumura \& Co., Ibaraki, Japan \\ Received 4 April 2004; accepted 29 June 2004 \\ Available online 7 August 2004
}

\begin{abstract}
Sho-saiko-to (SST) was introduced into Japan as an oriental classical medicine from China approximately 1500 years ago, and it is currently the most representative Kampo medicine (traditional Japanese medicine). SST is manufactured in Japan as an ethical drug on a modern industrial scale in which the quality of ingredients is standardized with Good Manufacturing Practices (GMP) regulation. SST is widely used for the treatment of chronic hepatitis. Experimental and clinical studies including multi-center, placebo-controlled, double-blind studies have demonstrated the various pharmacological effects of SST. SST is prepared from the hot water extraction of seven raw materials, therefore many kinds of constituents are included. Three-dimensional (3D) HPLC analysis is useful for obtaining many kinds of constituents, especially low molecular ultraviolet (UV) quenching compounds, contained in SST as well as its fractions. Fingerprint pattern provided by 3D HPLC analysis makes possible to identify the overall-viewing of SST. Databases of UV spectra of the components of medicinal herbs obtained by reversed-phase (RP) HPLC using a photodiode array (PDA) and fingerprint patterns of crude drugs made by 3D HPLC analysis facilitate the identification, analysis and quality of herbal drugs. Studies using both PDA HPLC and an amino acid analysis with a fluorometric detector have found that SST contains fifteen major low molecular compounds (i.e. baicalin, wogonin-7-O-glucuronide, liquiritin, their three aglycons, liquiritin apioside, glycyrrhizin, saikosaponin b1, saikosaponin b2, ginsenoside Rg1, ginsenoside Rb1, (6)-gingerol, (6)-shogaol and arginine). These compounds have various pharmacological actions, and are assumed to be responsible, at least partly, for the pharmacological effects of SST. Although there have only been a few investigations on high molecular compounds with pharmacological actions contained in SST, several kinds of polysaccharides have been isolated from constituent herbs of SST. This review paper summarizes analytical methods of separation, isolation and identification of compounds with biological activities from SST, which is a mixture drug of medicinal herbs. Accordingly, this paper would not focus on methods of separation, isolation and analysis of particular compounds from each constituent herb of SST.
\end{abstract}

(C) 2004 Elsevier B.V. All rights reserved.

Keywords: Reviews; Fingerprinting; Sho-saiko-to medicine

\section{Contents}

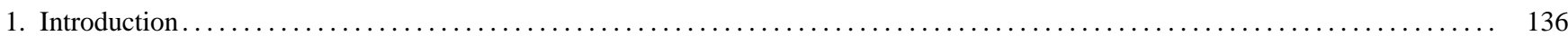

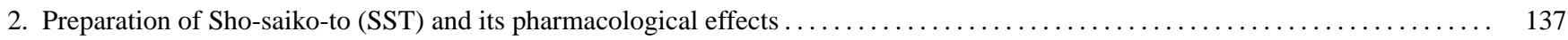

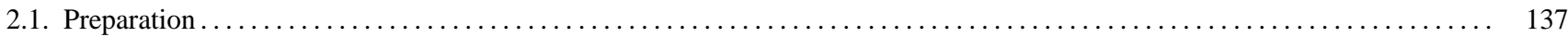

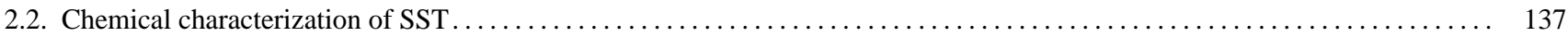

2.3. Use of three-dimensional (3D) HPLC analysis for profiling herbs and Kampo medicines . . . . . . . . . . . . . . . . . 138

* Corresponding author. Tel.: +8129889 3926; fax: +81298892158.

E-mail address: ootake_nobuhiro@mail.tsumura.co.jp (N. Ohtake). 


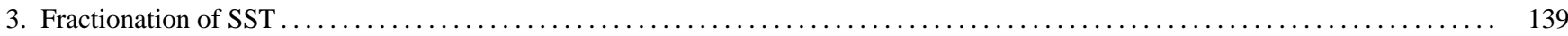

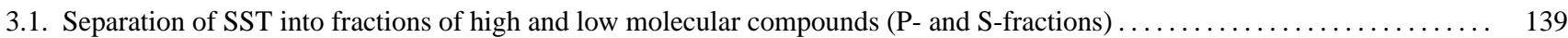

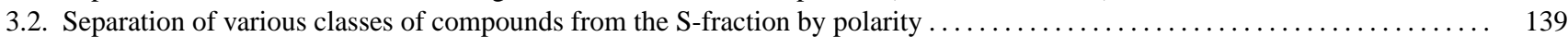

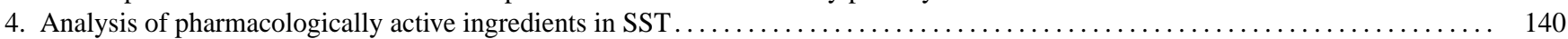

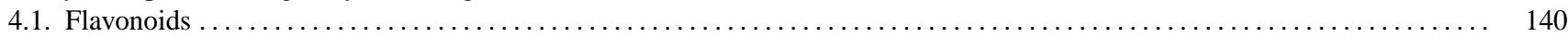

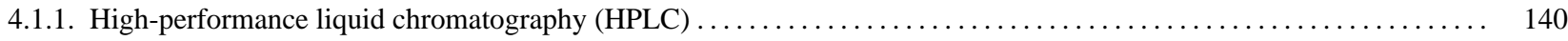

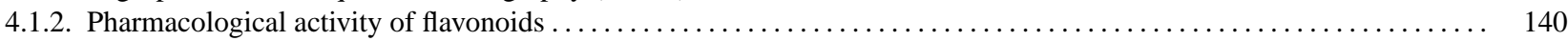

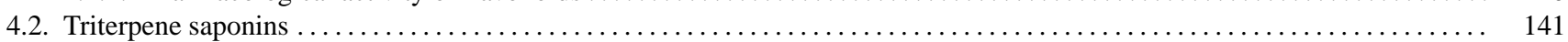

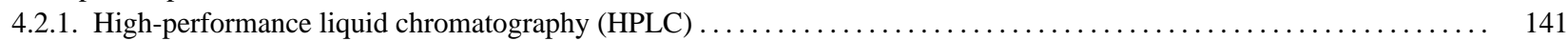

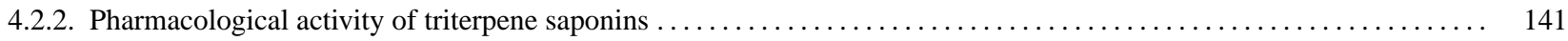

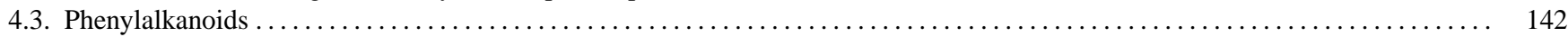

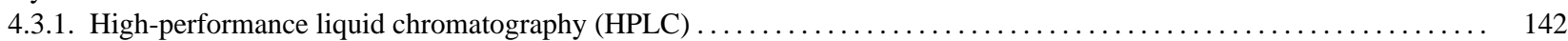

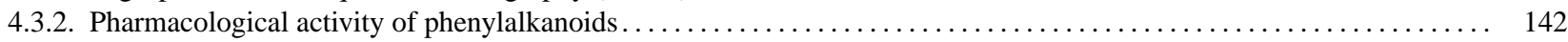

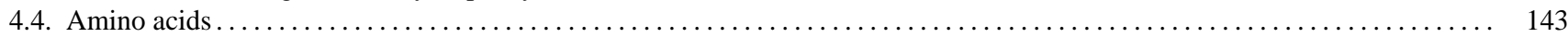

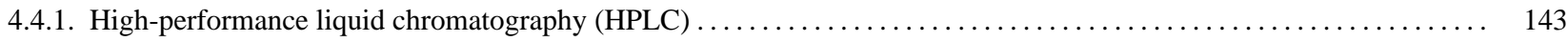

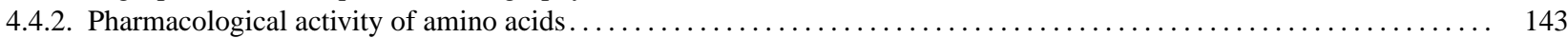

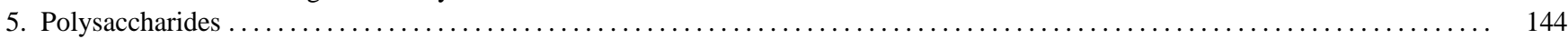

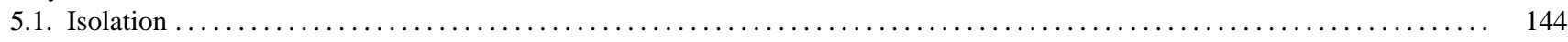

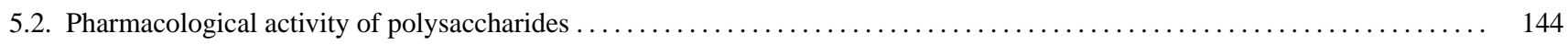

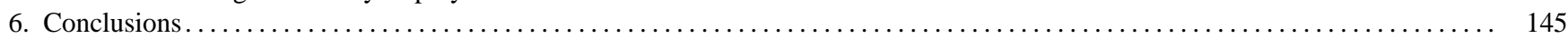

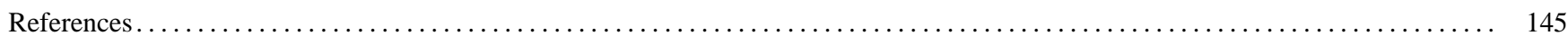

\section{Introduction}

"Kampo" medicine is a Japanese traditional medicine that had developed from the traditional herbal medicine originating in ancient China [1]. The primary mode of Kampo therapy is ingestion of Kampo formulas (i.e. specific combinations of raw herbs) written in classical texts, which are assumed to represent the culmination of empirical knowledge gained over the centuries. Chinese traditional medicine and Kampo medicine vastly differ from Western medicine, and even from Western herbal medicines, with regard to many points, for example, in philosophy, in the concepts of diseases, and in the therapeutic approach. Among the differences, in Chinese traditional medicine and Kampo medicine, herbs are generally used in combinations. The use of a single herb is exceptional. As a rule, herbs are mixed and then extracted with hot water. Some Kampo formulas contain herbs with similar pharmacological activity. Other Kampo formulas contain herbs with different, sometimes even conflicting, pharmacological properties. Many Kampo formulas with different properties and different indication of drug treatment contain common herbs such as Glycyrrhizae Radix. The unique strategy adopted by these oriental medicines is the use of the mixture of various medical herbs with pharmacologically active compounds that have additive and/or synergistic effects or reduce the harmful activities of some pharmacologically active compounds. The benefit of the strategy, however, is to be proved in the future, at least in terms of modern medical science. The combinatorial nature of Chinese traditional medicine and Kampo medicine makes it extremely difficult to identify the active compounds and to elucidate the mechanism of their pharmacological actions. There are an enormous number of compounds in a single Kampo formula, and the amount of each compound is minute. A single Kampo formula may contain different ingredients with similar bioactivity or similar ingredients with different, even antagonistic, bioactivity. Further, many compounds are commonly present in many different Kampo formulae that are used for the treatment of quite different diseases.

In Japan, a number of Kampo formulas are manufactured on a modern industrial scale in which the quality and quantity of ingredients are standardized under strict, scientific quality controls. Some of them have been demonstrated to have clinical therapeutic efficacy in contemporary scientific research studies including multi-center, placebo-controlled, doubleblind studies. Over one hundred Kampo formulas have been approved as ethical drugs by the Ministry of Health, Welfare and Labor of Japan, and are clinically used for the treatment of a wide variety of diseases. It has been reported that over the $80 \%$ of physicians in Japan who have been educated in Western medicine at Japanese medical schools have some experience in using Kampo medicines ethically [2]. Therefore, in Japan, the isolation, identification and analysis of the active compounds in Kampo formulas are not only a method for investigation of candidates for new drug development from an extraordinarily rich source, but also a method that is necessary for quality control and for elucidation of the pharmacological mechanisms of actions of the drugs now in use.

Sho-saiko-to (SST) is the most well-known Kampo medicine and has been widely used for the treatment of various inflammatory disorders such as chronic hepatitis, bronchitis, the common cold, pneumonitis, and enterogastritis. Long-term administration of SST has been used to treat approximately one million patients with chronic viral liver diseases, in order to improve liver dysfunction and to prevent the progression to liver fibrosis and carcinogenesis [3]. SST is a spray- or freeze-dried extract and consists of 
seven medicinal herbs. Phytochemical analysis of SST and modern scientific studies on its pharmacological actions were commenced about 30 years ago. Several clinical studies have demonstrated the therapeutic efficacy of SST in patients with chronic viral hepatitis [4,5]. Many experimental reports have demonstrated the pharmacological actions of SST. SST has anti-inflammatory [6-9], immunomodulating [10-17], and anti-oxidant effects [18-21], and it inhibits the progression or worsening of hepatic fibrosis [22-24], hepatitis [25-29], tumors [30-33], gastric injury [34], lung injury [35,36] and HIV proliferation/activity [37-39]. However, although many compounds with biological activities have been isolated and identified from the constituent herbs of SST, the active compounds responsible for each effect of SST described above have not been elucidated.

This review paper will mainly focus on methods of separation, isolation and analysis of compounds with biological activities in SST, which is a drug composed of a mixture of medicinal herbs. In addition, methods of profiling batches of SST by simultaneous analysis of the many compounds contained in SST and its constituent herbs, in order to evaluate and certify the quality of the drug will be described. The methods of separation, isolation and analysis of particular compounds from each constituent herb of SST will not be discussed.

\section{Preparation of Sho-saiko-to (SST) and its pharmacological effects}

\subsection{Preparation}

In the traditional method of preparing Kampo formulas, the constituent herbs are cut into pieces, mixed according to the instructions in the classical texts, decocted in hot water and ingested as a liquid extract. However, in recent years, technological advances have made it possible to manufacture the extract as a spray- or a freeze-dried powder with high standards of quality, uniformity and stability. SST consists of the powder extracted by hot water from the mixture of seven medical herbs that are registered in the Pharmacopoeia of Japan [40]. SST is currently prepared as follows. A mixture of $7.0 \mathrm{~g}$ of Radix of Bupleurum falcatum (Bupleurum Radix), $5.0 \mathrm{~g}$ of Tuber of Pinellia ternate (Pinelliae Tuber), $3.0 \mathrm{~g}$ of Radix of Scutellaria baicalensis (Scutellariae Radix), $3.0 \mathrm{~g}$ of Fructus of Zizyphus jujube (Zizyphi Fructus), $3.0 \mathrm{~g}$ of Radix of Panax ginseng (Ginseng Radix), $2.0 \mathrm{~g}$ of Radix of some species of Glycyrrhiza (i.e. uralensis, inflata or glabra) (Glycyrrhizae Radix), and 1.0 g of Rhizoma of Zingiber officinale (Zingiberis Rhizoma), in 10-fold weight of water is boiled for $60 \mathrm{~min}$ and filtered; then, the extract fluid is dried to obtain the extracted powder. Presently, Kampo medicines such as SST are manufactured according to the Ethical Kampo Medicine Drug GMP regulation and the self-imposed regulations of the Japan Kampo-Medicine Manufacturers Association.
Table 1

Different classes of compounds contained in the standardized Sho-saiko-to (SST) [133]

\begin{tabular}{ll}
\hline Class of compounds & Content $(\%)$ \\
\hline Starch, polysaccharides & 31.5 \\
Oligo-/monosaccharides & 24.7 \\
Organic compounds $^{\mathrm{a}}$ & 21.9 \\
Nitrogenated compounds & 8.9 \\
Free amino acids & 4.8 \\
Ash & 4.5 \\
Water, solvent & 3.4 \\
Lipids & 0.1 \\
Fiber & 0.2 \\
\hline
\end{tabular}

a Other than nitrogenated compounds and sugars.

\subsection{Chemical characterization of SST}

SST contains a large number of constituent compounds from various classes. The different classes of compounds present in the most widely used SST product (TJ-9, Tsumura \& Co., Tokyo, Japan) are shown in Table 1. All manufacturers of Kampo medicines as ethical drugs in Japan ensure that their extracts contain two or more of the major compounds that characterize the particular medicine group and that their extracts meet the criteria for a large number of other parameters. Chemical studies for investigation of the constituent compounds in Kampo medicines including SST or its component herbs, have generally been performed by HPLC analysis [41-43]. In recent years, HPLC combined with nuclear magnetic resonance (NMR) [44] or mass spectrometry (MS) [45] has been used to identify compounds in various herbs. These methods are powerful tools, especially when used to analyze certain types of compounds. However, in order to obtain an overall-viewing of as many compounds in a Kampo formula as possible at a glance, a PDA detector or an evaporative light scattering (ELS) detector is superior because Kampo medicines and herbs contain many classes of compounds with different physicochemical properties. In order to confirm the presence of many compounds qualitatively, analysis by gradient RP-HPLC is generally performed.

Many investigators have reported that each constituent medicinal herb of SST contains various low molecular compounds (LMC) (e.g., triterpene saponins, flavonoids, phenylalkanoids or amino acids) and high molecular compounds (HMC) (e.g., polysaccharides or proteins) (Table 2), using conventional isolation methods beginning with, for example, the extraction of a single herb by an organic solvent. However, it is difficult to detect many of these compounds in SST directly because: (1) SST is a mixture of seven medicinal herbs and therefore may contain a greater number of kinds of compounds in much smaller quantities than in each constituent herb; (2) SST is a hot water decoction and therefore the efficiency and profile of the extracted compounds are very different from those of the compounds extracted by an organic solvent from each herb; (3) the extraction of compounds with hot water often transforms the compounds to many different structures; (4) the presence of multiple herbs during the extraction process usually alters the profiles of the extracted 
Table 2

Biologically active compounds in the constituent herbs of SST

\begin{tabular}{|c|c|c|}
\hline Constituent herb & $\begin{array}{l}\text { Low molecular } \\
\text { mass compounds }\end{array}$ & $\begin{array}{l}\text { High molecular } \\
\text { mass compounds }\end{array}$ \\
\hline Bupleurum Radix & $\begin{array}{l}\text { (1) Saikosaponin a } \\
\text { (2) Saikosaponin c } \\
\text { (3) Saikosaponin d } \\
\text { (4) Arginine }\end{array}$ & (1) Bupleuran 2 \\
\hline Pinelliae Tuber & $\begin{array}{l}\text { (1) } \mathrm{PTH}^{\mathrm{a}} \\
\text { (2) } \mathrm{PTH}^{\mathrm{a}}\end{array}$ & $\begin{array}{l}\text { (1) Pinellian G } \\
\text { (2) Pinellian PA }\end{array}$ \\
\hline Scutellariae Radix & $\begin{array}{l}\text { (1) Baicalin } \\
\text { (2) Baicalein } \\
\text { (3) Wogonin-7-O- } \\
\text { glucuronoside } \\
\text { (4) Wogonin } \\
\text { (5) Skullcapflavone II } \\
\text { (6) Daidzein, } \\
\text { (7) Arginine }\end{array}$ & \\
\hline Zizyphi Fructus & $\begin{array}{l}\text { (1) Ethyl } \alpha \text {-D- } \\
\text { fructofuranoside }\end{array}$ & $\begin{array}{l}\text { (1) Polysaccharide } \\
\text { of MW: } 1.2 \times 10^{5} \\
\text { (2) Polysaccharide } \\
\text { of MW: } 43,000\end{array}$ \\
\hline Ginseng Radix & $\begin{array}{l}\text { (1) Ginsenoside R0 } \\
\text { (2) Ginsenoside Rb1 } \\
\text { (3) Ginsenoside Rb2 } \\
\text { (4) Ginsenoside Rb3 } \\
\text { (5) Ginsenoside Re } \\
\text { (6) Ginsenoside Rg1 } \\
\text { (7) Ginsenoside Rg2 } \\
\text { (8) 20(S)-Ginsenoside Rg3 } \\
\text { (9) } \Delta \text { 20-Ginsenoside Rg3 } \\
\text { (10) Ginsenoside Rh2 } \\
\text { (11) Ginsenoside Rf } \\
\text { (12) Panaxynol } \\
\text { (13) Arginine }\end{array}$ & $\begin{array}{l}\text { (1) Ginsenan PA } \\
\text { (2) Ginsenan PB } \\
\text { (3) Ginsenan S-IIA } \\
\text { (4) Ginsan }\end{array}$ \\
\hline $\begin{array}{l}\text { Glycyrrhizae } \\
\text { Radix }\end{array}$ & $\begin{array}{l}\text { (1) Liquiritin } \\
\text { (2) Liquiritin apioside } \\
\text { (3) Liquiritigenin } \\
\text { (4) Isoliquiritin } \\
\text { (5) Isoliquiritin apioside } \\
\text { (6) Isoliquiritigenin } \\
\text { (7) Glycyrrhizin } \\
\text { (8) Glycyrrhizic acid } \\
\text { (9) Glycycoumarin } \\
\text { (10) Genistein } \\
\text { (11) Licopyranocoumarin } \\
\text { (12) Licocoumarone } \\
\text { (13) Glycyrrhisoflavone }\end{array}$ & \\
\hline $\begin{array}{l}\text { Zingiberis } \\
\text { Rhizoma }\end{array}$ & $\begin{array}{l}\text { (1) (6)-Shogaol } \\
\text { (2) (6)-Gingerol } \\
\text { (3) (8)-Gingerol } \\
\text { (4) Zingerone } \\
\text { (5) Zingiberene } \\
\text { (6) 6-Gingesulfonic acid, } \\
\text { (7) Gingerglycolipid A } \\
\text { (8) Gingerglycolipid B } \\
\text { (9) Gingerglycolipid C } \\
\text { (10) } \beta \text {-Bisabolene, } \\
\text { (11) Arcurcumene }\end{array}$ & \\
\hline
\end{tabular}

a PTH-15 and PTH-16 were flavoniods reported by Maruno [134]. compounds compared to the profiles of the compounds extracted from each herb. Therefore, SST is not a mere summation of the extracts of each of its constituent herbs.

\subsection{Use of three-dimensional (3D) HPLC analysis for profiling herbs and Kampo medicines}

The HPLC profile of SST obtained using an ELS detector and UV detector according to the method described in Table 3, is shown in Fig. 1. HPLC analysis of SST using an ELS detector showed the presence of baicalin (BA) [46], glycyrrhizin (GL) [47] and saikosaponin b2 (SSb2) [48], which are the main compounds in Scutellariae Radix, Glycyrrhizae Radix and Bupleurum Radix, respectively (Fig. 1A). Analysis based on ultraviolet-visible (UV-vis) absorption showed that BA was the dominant compound and that GL and SSb2 were barely detectable (Fig. 1B), indicating that detection based on UV-vis absorption is less sensitive than ELS detection. However, when 3D HPLC analysis was used, data on the retention time and the UV-vis profile were obtained simultaneously. When the data on retention time and the UV-vis spectrum are integrated, it is easier to assign each peak by referring to the peaks of known compounds. For example, by comparing the UV-vis profile of 3D HPLC analysis of SST (Fig. 1B)
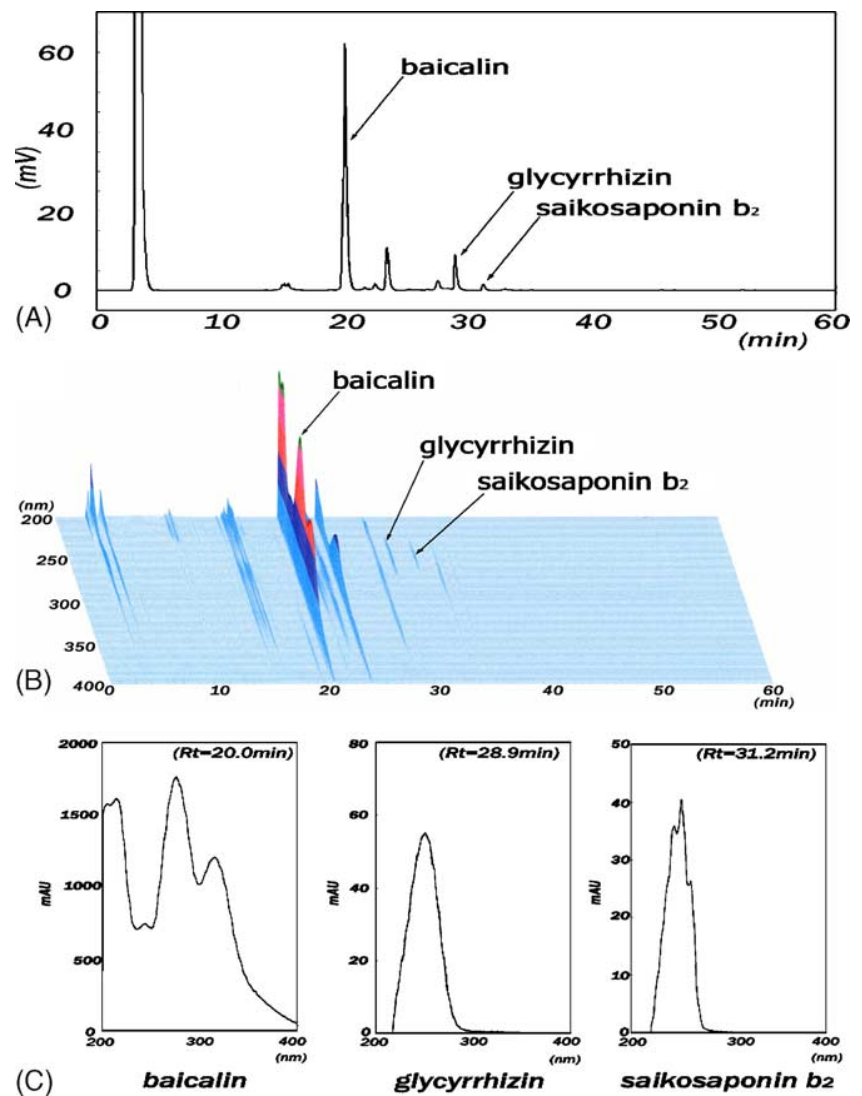

Fig. 1. ELSD/PDA-HPLC profiles of SST and UV-vis absorption spectra of baicalin, glycyrrhizin, and saikosaponin b2 obtained by a PDA detector. The procedure of HPLC analysis of SST is described in Table 3. HPLC profile with ELS detector (A), 3D HPLC analysis profile with PDA detector (B), UV-vis absorption spectra of compounds (C). 
Table 3

HPLC method for determination of the compounds in SST

(1) SST was extracted with $50 \%$ methanolic water under ultrasonication for 30 min, followed by centrifugation

(2) Analysis of the supernatant solution was performed with an HPLC apparatus equipped with two pumps, a photodiode-array (PDA)

detector, an evaporative light scattering (ELS) detector and an $5 \mu \mathrm{m} 250 \times 4.6 \mathrm{~mm}$ ODS column (ODS-80Ts, TOSOH, Tokyo, Japan) placed in a column oven

(3)

The mobile phase was a mixture of (A) $3 \mathrm{mM} \mathrm{CF}_{3} \mathrm{COOH}$ aq. and (B) $100 \% \mathrm{CH}_{3} \mathrm{CN}$ with a linear gradient changing rate from $90 \% \mathrm{~A}$ and $10 \% \mathrm{~B}$ to $100 \% \mathrm{~B}$ over $60 \mathrm{~min}$, and then $100 \% \mathrm{~B}$ was continued for $20 \mathrm{~min}$

(4) The flow rate of the mobile phase was $1.0 \mathrm{ml} / \mathrm{min}$ and the column temperature was $40^{\circ} \mathrm{C}$

(5) The UV data of the effluent from the column ranging from 200 to $400 \mathrm{~nm}$ were collected, and peak analysis and assignment were performed with the system analysis software (CLASS-LC10, Shimadzu, Kyoto, Japan)

(6)

Regarding peak identification by the PDA detector, it was conducted according to the method reported by Mito and Kitaoka [135] and by using the retention time. The UV-vis spectral curves of three points (head, top and tail) in each peak and the retention time were compared with those of authentic samples. The similarity of spectra was processed and calculated by the Shimadzu CLASS-LC10 processor

and the pre-established UV-vis profiles of BA, GL and SSb2 (Fig. 1C), we can assign the peaks corresponding to BA, GL and SSb2 in the 3D HPLC analysis chart. We have been constructing a database that includes the retention times, the UV-vis profiles of approximately 1000 compounds purified from various herbs, and more than 100 fingerprint patterns of Kampo medicines and constituent herbs made by 3D HPLC analysis. The database will enable us to provide not only a convenient method of assigning the constituent compounds contained in herbs and Kampo medicines, but also the means to control the quality of the extracts from a more comprehensive and global viewpoint by providing the "fingerprint" of each medicine/herb. In the following sections that describe methods of separation and isolation of various compounds with pharmacological actions (Fig. 2), the 3D HPLC analysis profiles of various fractions separated from SST will be shown to provide an overall-viewing of the fractions.

\section{Fractionation of SST}

\subsection{Separation of SST into fractions of high and low molecular compounds ( $P$ - and $S$-fractions)}

Because the techniques for analysis of LMC greatly differ from those of HMC, SST should be separated into a frac-

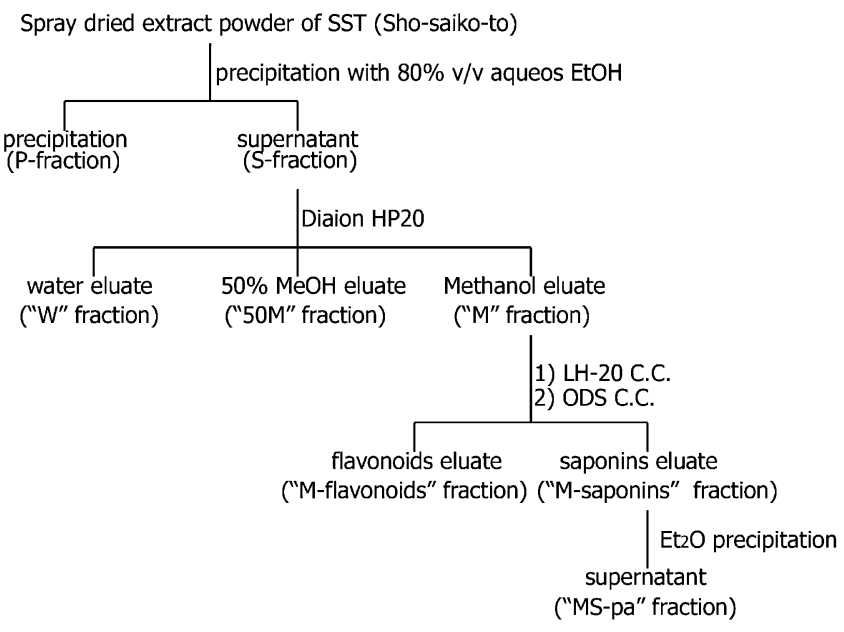

Fig. 2. Method of separation of pharmacologically active ingredients in SST. tion containing mainly LMC and a fraction containing mainly HMC. Several methods have been developed to remove HMC from Kampo medicines [17,49], and the method that is frequently used is as follows. SST is first dissolved in 10-fold weight of water and then ethanol is gradually added to its final concentration of $80 \%(\mathrm{v} / \mathrm{v})$ aqueous ethanol. After centrifugation at $1400 \times g$ at room temperature for $20 \mathrm{~min}$, the precipitate (P-fraction) and the supernatant (S-fraction) are each evaporated to dryness. The yield of $\mathrm{P}$ - or $\mathrm{S}$-fraction is typically ca. 41.3 and $50.2 \%$, respectively. To analyze the LMC in the S-fraction in detail, the S-fraction is subjected to further separation procedures as described in the following Sections 3.2, 4.1.1, 4.2.1, 4.3.1 and 4.4.1 according to their physicochemical properties (Fig. 2). Other investigators have developed methods of isolating polysaccharides with pharmacological activities from the P-fraction or from the constituent herbs of SST, which will be described in Section 5.1.

\subsection{Separation of various classes of compounds from the $S$-fraction by polarity}

Based on studies on the chemical characterization of the constituent herbs of SST [17,49-53], it is assumed that the $\mathrm{S}$-fraction contains various classes of compounds with different polarity and structure (i.e., flavonoids, triterpenes, saccharides, amino acids). Therefore, subsequent fractionations of the S-fraction are performed based on either the polarity or the structural properties of compounds.

As shown in Fig. 2, an aliquot of the S-fraction is subjected to adsorption column chromatography with a porous polymer gel (Diaion HP20, Mitsubishi Chemical Co., Tokyo, Japan) and successively eluted with water (W), 50\% aqueous methanol (50M), and methanol (M) (detailed conditions of the procedure, see Table 4). These eluents were concentrated under reduced pressure and then lyophilized to result in three fractions for analysis. The yield of the three fractions (W, $50 \mathrm{M}$ or $\mathrm{M}$ ) was approximately $77.1,12.9$, or $7.9 \%$ from the $\mathrm{S}$-fraction dried powder, respectively. The detailed procedure for separation of $\mathrm{M}$ fraction was shown in Table 5. Among the three fractions, $\mathrm{M}$ fraction was further fractionated by separation with Sephadex LH-20 (Pharmacia, Sweden) column chromatography and subsequently separation with octadecyl silica (ODS) (Cosmosil 140 C18-OPN, Nakarai 
Table 4

Method of separation of major low molecular compounds (LMC) from S-fraction

$100 \mathrm{~g}$ of S-fraction dried powder was dissolved in $5000 \mathrm{ml}$ water, and this was applied to a column on which $5000 \mathrm{~g}$ Diaion HP20 had been
packed
The adsorbed S-fraction with Diaion HP20 was successively eluted with $5000 \mathrm{ml}$ of water, $5000 \mathrm{ml}$ of $50 \%$ aqueous methanol and $5000 \mathrm{ml}$ of
$100 \%$ methanol
Each elution was evaporated to dryness

Table 5

Method of separation of major low molecular compounds (LMC) from M fraction

\begin{tabular}{ll}
\hline (1) & M dried powder was dissolved in $50 \% \mathrm{MeOH}$, and this was applied to a Sephadex $\mathrm{LH}-20 \mathrm{column}$ rinsed with $50 \% \mathrm{MeOH}$ \\
(2) & Gradient RP-HPLC from $50 \% \mathrm{MeOH}$ to $\mathrm{MeOH}$, to obtain three fractions, i.e. flavonoids, saponins and its mixture \\
(3) & $35 \% \mathrm{MeOH}$ solution of the flavonoids-saponins mixture was applied to the ODS column that had been rinsed with $35 \% \mathrm{MeOH}$ \\
(4) & Gradient RP-HPLC from $35 \% \mathrm{MeOH}$ to MeOH, to obtain two fractions, flavonoids and saponins \\
(5) & Each saponins fraction and flavonoids fraction is collected to dryness \\
(6) & The extract was filtered and concentrated to afford M-phenylalkanoid fractions \\
\hline
\end{tabular}

Chemicals Co. Ltd., Tokyo, Japan) column chromatography with aqueous-methanol gradient eluting. The eluted fraction were collected, pooled, and then checked by RP HPLC analysis using a PDA detector. As a result, two fractions, i.e., a fraction enriched with saponins (M-saponins) and a fraction enriched with flavonoids (M-flavonoids), are obtained from the $\mathrm{M}$ fraction. The yield of each fraction is roughly estimated to be 58 or $42 \%$, respectively. Furthermore, to separate phenylalkanoid compounds from the M-saponins, the M-saponins were extracted with diethyl ether under sonication at room temperature. The diethyl ether extract was filtered with a $4 \mu \mathrm{m}$ pore size filter and dried to a powder to result in the phenylalkanoid-enriched fraction (MS-pa), and the yield of the fraction was approximately $9 \%$ from M-saponins fraction.

\section{Analysis of pharmacologically active ingredients in SST}

\subsection{Flavonoids}

\subsubsection{High-performance liquid chromatography (HPLC)}

Fifty percent aqueous methanol (50M) fraction is thought to contain various compounds with a structure similar to flavonoids, since the separation method was adsorption chromatography with a porous polymer gel. To analyze the flavonoid derivative compounds in SST, both $50 \mathrm{M}$ and Mflavonoids fractions should be analyzed. A HPLC apparatus equipped with a PDA detector with a ODS column was used. The UV data of the effluent from a column ranging from 200 to $400 \mathrm{~nm}$ were collected, and peak analysis and assignment were performed using reference compounds that had been isolated from the constituent herbs of SST (for analytical conditions, see Table 6). By peak assignment of the retention times and UV absorption patterns, the HPLC profiles of $50 \mathrm{M}$ and $\mathrm{M}$-flavonoids fractions showed five compounds (i.e., liquiritin (LQ) [54], liquiritin apioside (LA) [55], $\mathrm{BA}$, oroxylin-A-7-O-glucuronide (OAG) [56] and wogonin-
7-O-glucuronide (WGG) [56]) (Fig. 3). On the other hand, the HPLC profile of M-flavonoids fraction showed eight compounds (i.e., isoliquiritin (ILQ) [57], isoliquiritin apioside (ILA) [58], OAG, WGG, baicalein (BE) [59], wogonin (WG) [60], oroxylin-A (OA) [59] and liquiritigenin (LG) [60]) (Fig. 4). Therefore, 11 flavonoid compounds which are known to be major compounds in Glycyrrhizae Radix or Scutellariae Radix, were detected in SST, and their structures are shown in Fig. 5.

\subsubsection{Pharmacological activity of flavonoids}

It has been reported that when SST is administered orally, flavonoid glucosides are absorbed either directly or their aglycones after intestinal hydrolysis of glycosides [61,62], while flavonoid aglycons are absorbed directly without modification.

Orally administered SST increased the IL-6 level in the lung tissues of BALB/c mice [63]. LG, a metabolite of LQ produced by intestinal hydrolysis [62], but not LQ itself, has been reported to increase IL- 6 production in cultured lung mononuclear cells, although whether the effect of SST is due to the effect of LG has not been determined yet [63]. Oral administration of LA, but not LQ, to guinea pigs was shown to inhibit coughing via effects on both the peripheral

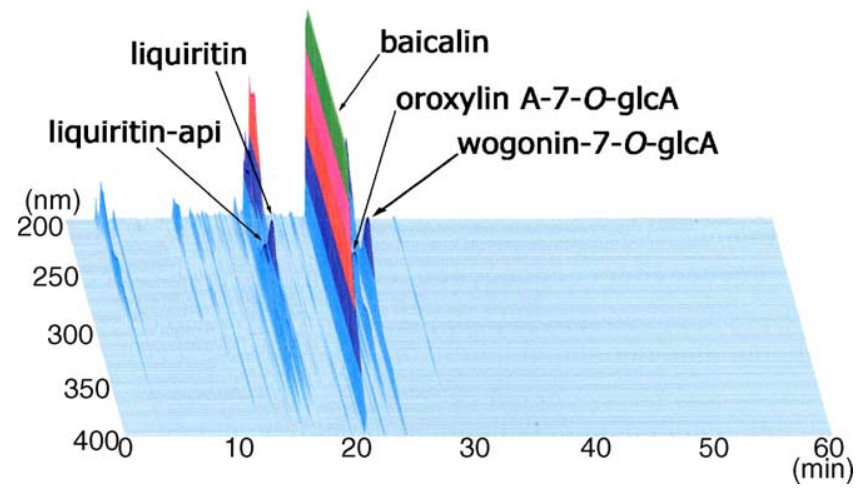

Fig. 3. Three-dimensional (3D) HPLC analysis profiles of the 50M fraction separated from SST. The chromatographic conditions are described in Table 6. 
Table 6

HPLC method for isolation and analysis of compounds in 50M and three fractions (M-flavonoids, M-saponins and MS-pa) that had been separated from M fraction

(1) Each fraction was extracted with methanol under ultrasonication for 30 min, followed by centrifugation

(2) Analysis of the supernatant solution was performed with an HPLC apparatus (Shimadzu, Kyoto, Japan) equipped with two pumps, a photodiode-array (PDA) detector and an ODS column placed in a column oven

(3) The mobile phase was a mixture of (A) $20 \mathrm{mM} \mathrm{H}_{3} \mathrm{PO}_{4}$ aq. and (B) $100 \% \mathrm{CH}_{3} \mathrm{CN}$ with a linear gradient rate of $90 \% \mathrm{~A}$ and $10 \% \mathrm{~B}$ changing over $60 \mathrm{~min}$ to $100 \% \mathrm{~B}$. Then $100 \% \mathrm{~B}$ was continued for $20 \mathrm{~min}$

(4) The flow rate of the mobile phase and the column temperature were $1.0 \mathrm{ml} / \mathrm{min}$ or $40^{\circ} \mathrm{C}$, respectively

(5) The UV data of the effluent from the column ranging from 200 to $400 \mathrm{~nm}$ were collected, and the peak analysis and assignment were performed with the system analysis software (CLASS-LC10, Shimadzu, Kyoto, Japan)

This is a partial modification of the method reported by Nakai et al. [136].

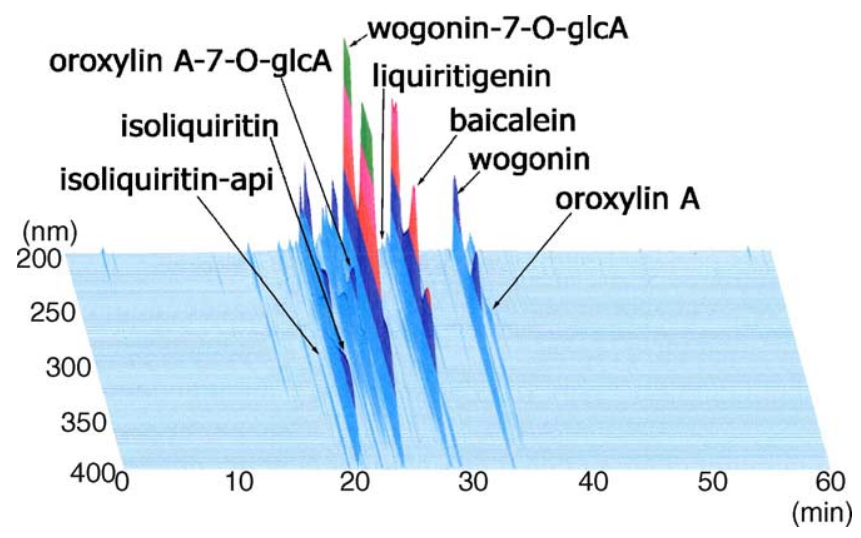

Fig. 4. Three-dimensional (3D) HPLC analysis profiles of the M-flavonoids fraction. The chromatographic conditions are described in Table 6.

and central nervous systems [64]. These effects are assumed to be related to the known efficacy of SST for pulmonary disorders. Upon oral administration of SST, BA, the most abundant LMC in SST, and BE, a metabolite of BA produced by hydrolysis by intestinal flora [62], were detected in the plasma of rats $[65,66]$. The pharmacological effects of BA and $\mathrm{BE}$ in experimental studies include an inhibitory effect on carrageenan-induced edema [67,68], ELAM-1 and ICAM-1 expression [69], IL-1 $\beta$ production [70], LPS-induced nitric oxide production, lipid peroxidation $[71,72]$, proliferation of a human cancer cell line [73], induction of cancer cell apoptosis [74,75] and anti-viral activities against HIV-1 [76]. Upon

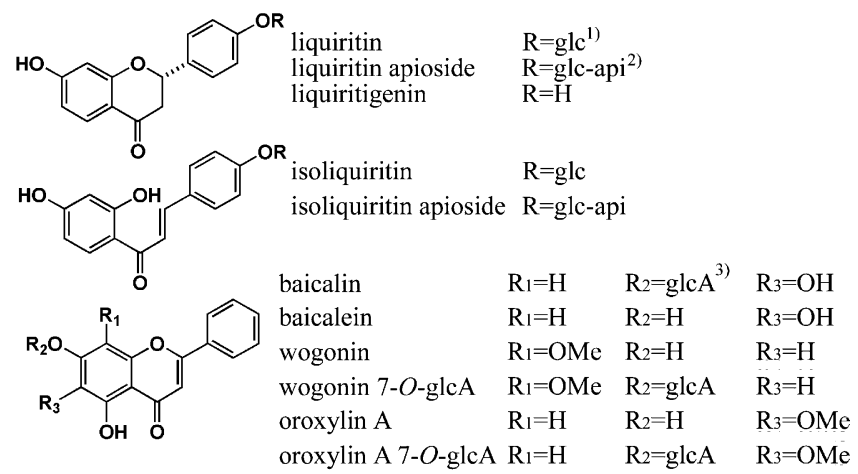

Fig. 5. Structures of the detected compounds in the 50M and M-flavonoids fractions. 1, glc is a D-glucopyranonose; 2, api is a D-apiofuranose; 3, glcA is a D-glucuronic acid. oral administration of WGG or SST $[61,62]$, WG, a metabolite of WGG, has been produced in vivo and reported to have anti-inflammatory effects, inhibitory effects on $\mathrm{PGE}_{2}, \mathrm{LTB}_{4}$ and $\mathrm{C}_{4}$ syntheses [77], anti-oxidant activity [78], suppression of expression of IL-6 and IL-8, and suppression of NFkappaB activation [79]. Thus, LQ, LA, BA, BE and WG are presumed to be the active principles in SST that are responsible for the pharmacological effects of SST.

\subsection{Triterpene saponins}

\subsubsection{High-performance liquid chromatography (HPLC)}

Analysis of M-saponins fraction was performed by a HPLC apparatus equipped with a PDA detector using an ODS column. UV data of the effluent from the column ranging from 200 to $400 \mathrm{~nm}$ were collected, and peak analysis and assignment were performed using standard samples that had been isolated from raw materials (for analytical conditions, see Table 6). Based on the retention times and UV absorption patterns, the PDA HPLC profile of M-saponins fraction showed five triterpenoidal saponins (i.e., ginsenoside $\mathrm{Rg} 1$ (GSRg1) [80], ginsenoside Rb1 (GSRb1) [81], GL, SSb2 and saikosaponin b1 (SSb1) [82]) (Fig. 6). It is suggested that these triterpene saponins were derived from Ginseng Radix, Glycyrrhizae Radix and Bupleurum Radix. Their structures are shown in Fig. 7.

The extract of Bupleurum Radix made by an organic solvent under slight alkalinity, contains large amounts of saikosaponin a (SSa) and saikosaponin d (SSd), and small amounts of SSb1 and SSb2. However, when the hot water extract of SST is made from the mixture of seven herbs, SSa and SSd are transformed into SSb1 and SSb2 by acid hydrolysis of the ester bond at C-13 and C-28 [83]. Consequently, SST contains moderate amounts of SSb1 and SSb2, but small amounts of SSa and SSd. The detection of triterpene saponins in SST thus demonstrates the complexity of the analysis of Kampo medicines.

\subsubsection{Pharmacological activity of triterpene saponins}

GL, a major compound in Glycyrrhiziae Radix (licorice; the root of Glycyrrhizia spp.), is frequently used for the treatment of hepatitis in Japan and is administered as a single com- 


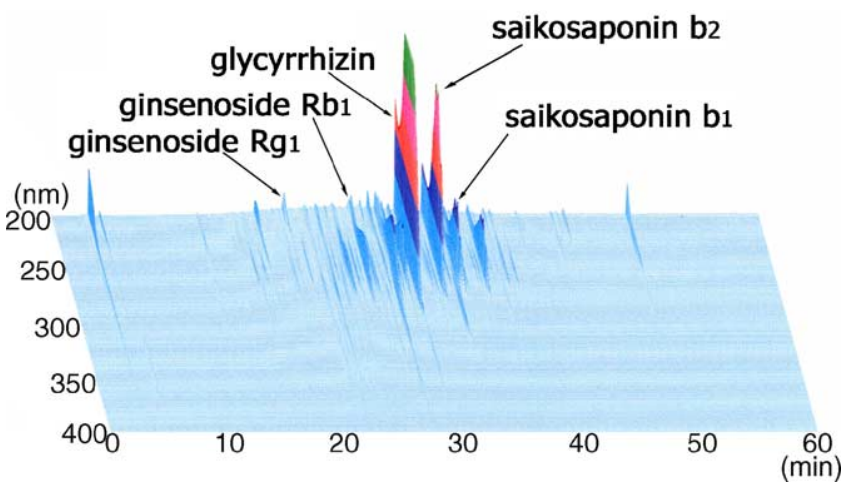

Fig. 6. Three-dimensional (3D) HPLC analysis profiles of the M-saponins fraction. The chromatographic conditions are described in Table 6.

pound ethical drug mainly by intravenous injection. Many clinical and experimental studies on GL have reported its therapeutic efficacy [84]. On the other hand, it has been noted that a number of side effects are happened in the subjects receiving high dose of GL or licorice extract [85] including pseudoaldosteronism [86]. The contribution of GL to the pharmacological effect of SST is still unclear. Upon oral administration of SST, glycyrrhizic acid (GA), an aglycon of GL, but not GL itself, has been detected in the plasma of the rats $[87,88]$, and a few detailed studies on the pharmacokinetics of GL and its metabolites upon oral administration of SST, have been performed. GL and GA have a wide variety of pharmacological effects, including hepatoprotective [89,90], immunomodulatory [91-93], anti-inflammatory [94,95], anti-mutagenic [96,97] and antiulcer effects [98]. Inhibitory effect of GL on HIV- [99] and SARS-associated coronavirus [100] has been also reported. Upon oral administration of SST, SSa and SSd in the SST extract are transformed to SSb1 and SSb2, respectively, by hydrolysis by the gastric juice [101]. Although SSb1 and SSb2 have not been directly demonstrated to have pharmacological activities, oral administration of SSa and SSd had an anti-granulomatous effect in a cotton pellet-induced granulomatous model [102], and intraperitoneal administration of SSb1 and SSb2 increased the plasma adrenocorticotropin and corticosterone levels in animal models $[103,104]$. These reports suggested that SSb1 and $\mathrm{SSb} 2$ have an anti-inflammatory property. The detectable peaks of GSRb1 and GSRg1 were rather small as shown in Fig. 6, however, these compounds were demonstrated to have multiple, potent, pharmacological actions even in trace amounts $[105,106]$. GSRg1 was demonstrated to increase the number of helper T cells, induce mitogenic activity of T cells by augmentation of IL-1 production [107], enhance expression of the IL-2 receptor $\alpha$ chain, increase intracellular levels of cAMP and cGMP in vitro [108], and inhibit the release of soluble IL-2 receptor [109].

\subsection{Phenylalkanoids}

\subsubsection{High-performance liquid chromatography (HPLC)}

Analysis of MS-pa fraction was performed by an HPLC apparatus equipped with a PDA detector using an ODS column. The UV data of the effluent from the column ranging from 200 to $400 \mathrm{~nm}$ were collected, and peak analysis and assignment were performed using a reference compound that had been isolated from raw materials (for analytical conditions, see Table 6). Based on the retention times and UV absorption patterns, two phenylalkanoids (i.e., (6)-gingerol and (6)-shogaol [110]) were detected in the PDA HPLC chromatogram of MS-pa fraction (Fig. 8). The structures of the two phenylalkanoids, which are the major compounds in Zingiberis Rhizoma, are shown in Fig. 9.

\subsubsection{Pharmacological activity of phenylalkanoids}

Ginger powder ameliorated rheumatoid arthritis in patients [111], and the hot water extract of ginger potently inhibited cyclooxygenase-2 (COX-2) enzyme activity [112]. (6)-Gingerol and (6)-shogaol were demonstrated to inhibit prostaglandin synthetase activity; further, (6)-shogaol inhibited 5-lipoxygenase activity [113]. In addition, (6)-shogaol was identified to inhibit carrageenin-induced swelling in rats and arachidonic acid-induced platelet aggregation in rabbits [114]. Yamahara et al. [115,116] confirmed that an acetone extract of ginger, zingiberene, a major terpenoid from the ace-
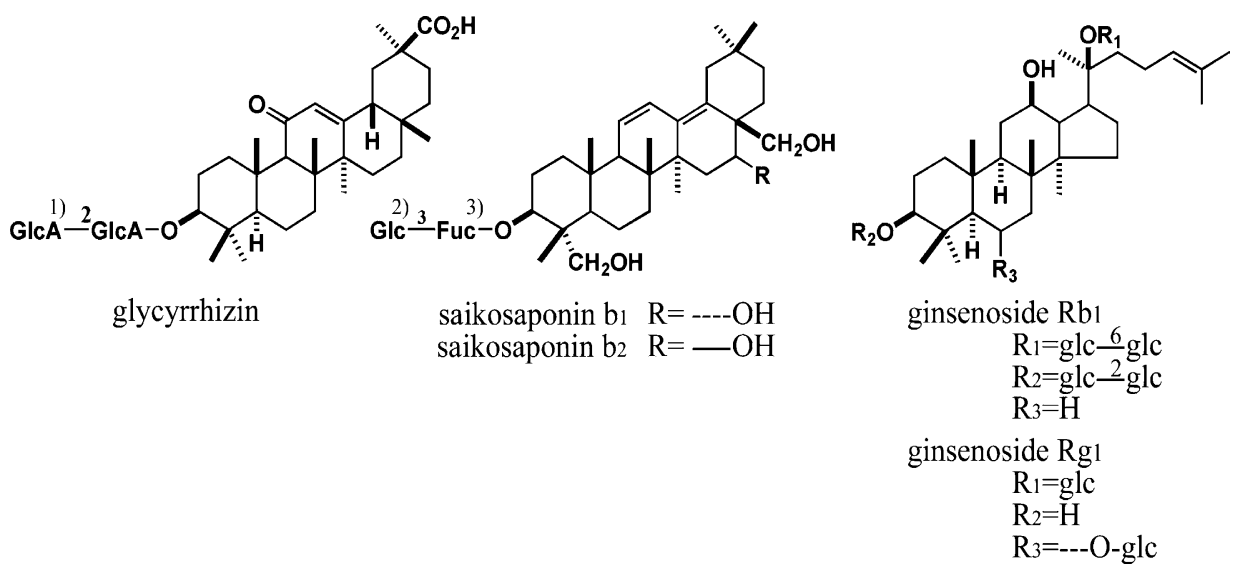

Fig. 7. Structures of the detected compounds in the M-saponins fraction. 1, glcA is a D-glucuronic acid; 2, glc is a D-glucopyranonose; 3 , fuc is a fucose. 


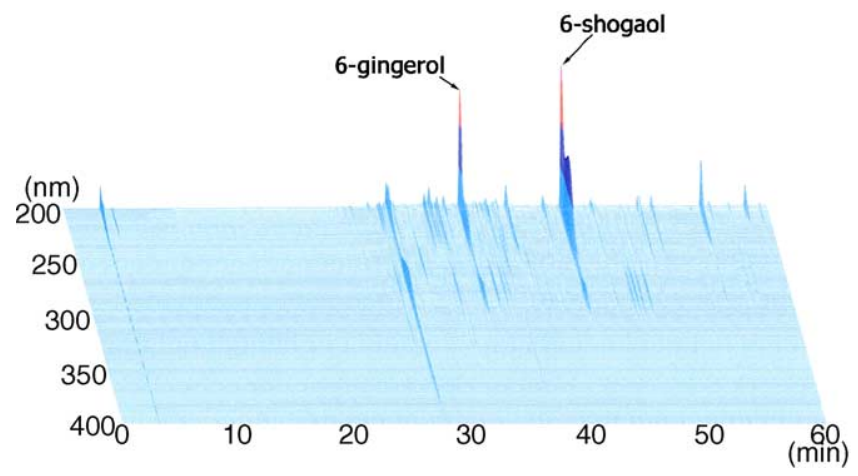

Fig. 8. Three-dimensional (3D) HPLC analysis profiles of the MS-pa fraction. The chromatographic conditions are described in Table 6.<smiles>CCCCCC[C@H](O)CC(=O)CCc1ccc(O)c(OC)c1</smiles><smiles>CCCCCC/C=C/C(=O)CCc1ccc(O)c(OC)c1</smiles>

Fig. 9. Structures of the detected compounds in the MS-pa fraction.

tone extract of ginger, and (6)-gingerol significantly inhibited the development of $\mathrm{HCl} /$ ethanol-induced gastric lesions in rats. These reports suggest that (6)-gingerol and (6)-shogaol may play roles in SST as stomachic medications.

\subsection{Amino acids}

\subsubsection{High-performance liquid chromatography (HPLC)}

Few studies on the phytochemical analysis of the amino acids contained in SST have been reported. Hayasaka et al. [117] reported that the amino acids contained in SST were predominantly arginine, and that other amino acids were present in trace amounts. They analyzed the amino acids contained in SST using an HPLC apparatus equipped with a postcolumn fluorometric detection system using a cation exchange column by reaction with $o$-phthalaldehyde. To enrich the amino acids in SST, the fractionation method has been performed with cation exchange resins [118]. We analyzed the W

Table 7

Analytical method for amino acids

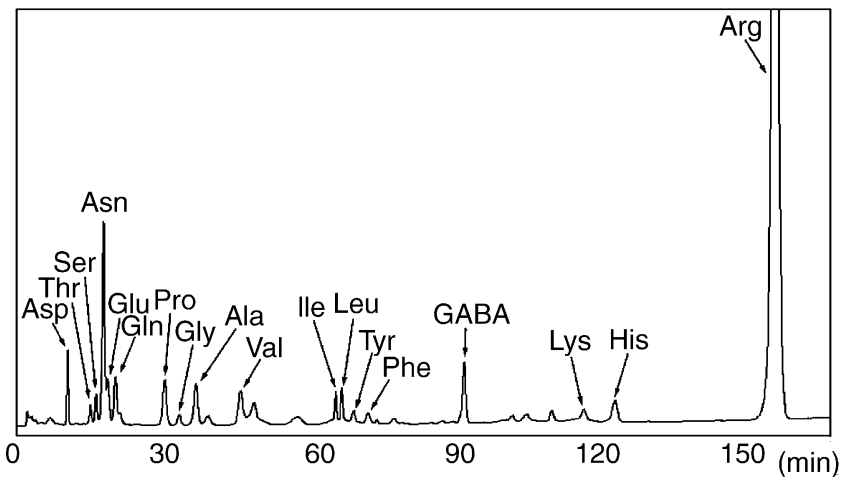

Fig. 10. HPLC profiles of the amino acids in the $\mathrm{W}$ fraction of SST. The chromatographic analysis conditions are described in Table 7. The HPLC profile of the $\mathrm{W}$ fraction mainly shows the presence of arginine.

fraction without further purification because the major constituents of W-fraction were only amino acids and oligo/mono saccharides. Analysis of the amino acids contained in the $\mathrm{W}$ fraction was performed using a cation-exchange column with an automatic amino acid analyzer equipped with a postcolumn fluorometric detection system, by reaction with alkaline hypochlorite and $o$-phthalaldehyde/2-mercaptoethanol (for analytical conditions, see Table 7). The HPLC profile of the W-fraction showed that SST contains mainly arginine (Fig. 10).

\subsubsection{Pharmacological activity of amino acids}

L-Arginine has been known to be genetically coded essential amino acid, precursor for the synthesis of nitrogen containing compound in the body (e.g. nitric oxide, creatine phosphate). It has been reported that an acidifying agent L-arginine can improve cardiovascular disease in man as dietary supplement [119]. The immunostimulating effect of Larginine has been also reported [120] though it is unclear whether L-arginine is responsible for similar immunomodulating effects by SST. Further, L-arginine was demonstrated to prevent the development of gastric ulcer in experimental and clinical studies [121-123]. SST is used for the treatment of enterogastritis in traditional Kampo therapy and has been demonstrated to suppress gastric injury and gastric juice se-

(1) The $\mathrm{W}$ fraction was extracted with $0.2 \mathrm{~N}$ sodium-citrate- $\mathrm{HClO}_{4}$ buffer ( $\mathrm{pH} 2.2$ ) under ultrasonication for 30 min

(2) The solution is obtained after centrifugation at $3000 \mathrm{rpm}$ at room temperature for $10 \mathrm{~min}$, and the supernatant was filtered through a $0.45 \mu \mathrm{m}$ membrane

(3) HPLC on a $5 \mu \mathrm{m}, 100 \mathrm{~mm} \times 6 \mathrm{~mm}$ cation exchange polymer column (AApack Na, Jasco, Tokyo, Japan), $0.6 \mathrm{ml} / \mathrm{min}$ with next eluent program
(a) $\mathrm{pH} 2.97$
(b) $\mathrm{pH} 3.28$
(c) $\mathrm{pH} 4.25$
(d) $\mathrm{pH} 3.75$
(e) $\mathrm{pH} 4.55$

The fluorometric data of the effluent from the column were obtained with excitation at $350 \mathrm{~nm}$ and emission at $440 \mathrm{~nm}$ in under the reaction condition of post reaction systems (a temperature reaction coil (TJ-100, Jasco, Tokyo, Japan) with both a flow rate reagents (o-phtaladehyde and $\mathrm{NaOCl}$ ) at $0.4 \mathrm{ml} / \mathrm{min}$ and a temperature reaction coil at $40^{\circ} \mathrm{C}$. The peak analysis and assignment of the reagent were performed using the system analysis software 
cretion in various experimental models [34], although the active principle in SST that is responsible for this effect has not been determined.

\section{Polysaccharides}

\subsection{Isolation}

The yield of the P-fraction (Fig. 2) separated from SST was $41.3 \%$, and this fraction is assumed to contain various macromolecules such as polysaccharides. Several authors have reported that macromolecules with pharmacological activities have been isolated from the constituent herbs of SST (i.e., Zizyphi Fructus, Bupleurum Radix, Ginseng Radix and Pinelliae Tuber) [124,125], there have only been a few studies on identification of the macromolecules. Yamaoka et al. [17] isolated and determined the composition of the sugar moiety in the fraction consisting of pure acid polysaccharide which can augment natural killer (NK) activity from SST, although its structure has not been determined yet. This fraction was prepared by extraction with $n$ butanol, precipitation by cetyltrimethylammonium bromide, and DEAE-Sephadex column chromatography. As a result, a polysaccharide fraction (fraction 12) with the chemical properties shown in Table 8 was separated from SST. From several SST constituent herbs (i.e., Bupleurum Radix, Pinelliae Tuber and Ginseng Radix), Yamada and coworkers [126-128] purified and determined the sugar compositions and, in some cases, the structures of the polysaccharides that have antiulcer or anti-complementary effects, that promote B cells proliferation and/or that induce the expression of cell cycle regulatory proteins. For example, the crude polysaccharide fraction that had been prepared by hot-water extraction and ethanol precipitation from Bupleurum Radix, was fractionated by treatment with cetyltrimethylammonium bromide into four polysaccharide fractions. The most acidic fraction was further fractionated on DEAE-Sepharose column chromatography by stepwise elution with $\mathrm{NH}_{4} \mathrm{HCO}_{3}$ to bupleuran 2IIb, c, d, and e. Bupleuran 2IIb and c are each a homogenous pectin-like polysaccharide consisting of a large polygalacturonan region and a small rhamnogalacturonan region. Structural characterization of these polysac-
Table 8

Chemical properties of fraction 12

\begin{tabular}{ll}
\hline Molecular weight & $1.2 \times 10^{5}$ \\
Total protein (as BSA ${ }^{\mathrm{a}}$ ) & $\mathrm{ND}^{\mathrm{b}}$ \\
Total carbohydrate (as Glc) (\%) & 70.2 \\
Total uronic acid (as GlcA) (\%) & 40.4 \\
\hline Component sugars & Molar ratios \\
\hline Rhamnose & 1 \\
Mannose & 3 \\
Arabinose & 17 \\
Galactose & 21 \\
Glucose & 100 \\
Galacturonic acid & 87 \\
\hline Fraction 12 from SST was reported to have augmentation of NK activity \\
[17]. \\
$\quad$ a Bovine serum albumin. \\
$\quad$ b Not detected.
\end{tabular}

charides has been performed by gel filtration, HPLC and electrophoresis, NMR studies, methylation analysis before and after reduction of carboxyls, Smith degradation, digestion with endo-polygalacturonase, base-catalyzed betaelimination, enzymatic hydrolysis, etc. Ginsenan PA and PB have been isolated and characterized by similar procedures [129].

\subsection{Pharmacological activity of polysaccharides}

Various polysaccharides in the constituent medical herbs of SST have pharmacological effects as shown in Table 9. For example, it has been demonstrated that a fraction consisting of $4.3 \times 10^{4}$ molecular weight compound isolated from Zizyphi Fructus augments natural killer (NK) activity [124], BR-2IIb and BR-5-I fractions from Bupleurum Radix $[130,131]$ and ginsenan PA and ginsenan PB from Ginseng Radix have anti-complementary activity [127,129] and ginsenan S-IIA in Ginseng Radix has immunomodulating activity [132]. The BR-2IIc from Bupleurum Radix has been reported to prevent ulcerogenesis [126]. A fraction isolated from SST (fraction 12; Table 8) that augments NK activity in the peripheral blood was identified [17]. Orally administered SST was reported to enhance NK activity [10] and suppress gastric injury and gastric juice secretion in various experimental models [34]. These polysaccharides

Table 9

Pharmacological activities of high molecular compounds in the constituent herbs of SST

\begin{tabular}{|c|c|c|c|c|}
\hline Constituent herb & Name of compound & MW & Pharmacological activity & Reference $^{\mathrm{a}}$ \\
\hline Bupleurum Radex & Bupleuran 2IIc & $6.3 \times 10^{3}$ & Anti-ulcer & [137] \\
\hline Pinelliae Tuber & $\begin{array}{l}\text { Pinellian G } \\
\text { Pinellian PA }\end{array}$ & $\begin{array}{l}1.5 \times 10^{4} \\
11.8 \times 10^{4}\end{array}$ & $\begin{array}{l}\text { Anti-complement } \\
\text { Anti-complement }\end{array}$ & $\begin{array}{l}{[138]} \\
{[139]}\end{array}$ \\
\hline Zizyphi Fructus & $-($ fraction 5) & $4.3 \times 10^{4}$ & Augmentation of NK activity & {$[124]$} \\
\hline Ginseng Radix & $\begin{array}{l}\text { Ginsenan PA } \\
\text { Ginsenan PB } \\
\text { Ginsenan S-IIA }\end{array}$ & $\begin{array}{l}1.6 \times 10^{5} \\
5.5 \times 10^{4} \\
1.0 \times 10^{5}\end{array}$ & $\begin{array}{l}\text { Anti-complement } \\
\text { Anti-complement } \\
\text { Anti-complement }\end{array}$ & $\begin{array}{l}{[129]} \\
{[129]} \\
{[140]}\end{array}$ \\
\hline
\end{tabular}

${ }^{a}$ Reports of both the phytochemical characters of a compound and its pharmacological activities. 
Table 10

HPLC detected compounds in fractions that had been separated from S-fraction

\begin{tabular}{|c|c|c|c|c|}
\hline W & $50 \mathrm{M}$ & M-flavonoids & M-saponins & MS-pa \\
\hline $\begin{array}{l}\text { Arginine, } \\
\text { asparagines, etc. }\end{array}$ & $\begin{array}{l}\text { Liquiritin, liquiritin apioside, } \\
\text { baicalin, } \\
\text { wogonin-7-O-glucuronide, } \\
\text { oroxylin-A-7- } O \text {-glucuronide }\end{array}$ & $\begin{array}{l}\text { Baicalin, baicalein, wogonin, } \\
\text { wogonin- } O \text {-glucuronide, } \\
\text { liquiritigenin, oroxylin-A, } \\
\text { oroxylin-A-7- } O \text {-glucuronide, } \\
\text { liquiritigenin, isoliquiritin, } \\
\text { isoliquiritin apioside }\end{array}$ & $\begin{array}{l}\text { Glycyrrhizin, saikosaponin b1, } \\
\text { saikosaponin b2, ginsenoside Rg1, } \\
\text { ginsenoside Rb1 }\end{array}$ & $\begin{array}{l}\text { (6)-Shogaol, } \\
\text { (6)-gingerol }\end{array}$ \\
\hline
\end{tabular}

may be responsible for the above-mentioned effects of SST, although further investigations are required.

\section{Conclusion}

SST is the most representative Kampo medicine in Japan, and has been ethically used for the treatment of inflammatory diseases, especially chronic hepatitis. Many clinical and experimental studies have demonstrated the various pharmacological effects of SST. SST, a hot water extract of the mixture of seven medical herbs, is assumed to contain many LMC and HMC, and both groups of compounds have been demonstrated to have important pharmacological activities [49]. Phytochemical analysis of the LMC in the constituent herbs of SST has been performed by a number of investigators, and many LMC have been isolated, characterized, and proven to have biological activities. HMC, typically polysaccharides, have also been isolated and characterized, and their pharmacological activities were demonstrated, although there have only been a few studies on HMC. Nevertheless, the possible contributions of the above-mentioned compounds to the various pharmacological effects of SST remain to be clarified. The combinatorial use of multiple herbs and extraction by hot water, which are characteristics of Kampo medicines, make phytochemical and pharmacological analyses of SST extremely difficult. In addition, because Kampo medicines are manufactured as highly standardized ethical drugs in Japan, a method of comprehensive analysis of the compounds for scientific quality control is urgently needed.

Therefore, the present review is focused on the following two points. (1) Methods of separation, isolation and analysis of compounds in SST, which is a mixture of medicinal herbs, were discussed. The isolation of compounds from a single herb was not described. (2) The compounds in SST and its fractions were profiled by 3D HPLC analysis. With this method, comprehensive analysis of LMC in SST can be performed and used for quality control of crude drugs. Despite recent advances in the separation, isolation and analytical methods, and despite the many phytochemical studies on the compounds in the constituent herbs of SST, the problems of the establishment of comprehensive methods for analyses of the macromolecular compounds in SST have been essentially unsolved. A breakthrough in the methodology for comprehensive analysis of many compounds and the separation, isolation, and identification of macromolecular compounds (especially polysaccharides) is much awaited.

The methods of phytochemical analysis for the separation/detection of low and high molecular weight compounds in SST that are assumed to be the active principles in SST, are summarized as follows. Upon sedimentation with $80 \%$ ethanol, the $\mathrm{S}$ fraction (enriched with low molecular weight compounds) and $\mathrm{P}$ fraction (enriched with high molecular weight compounds) are separated. The $\mathrm{S}$ fraction is subsequently separated into five fractions (i.e., W, 50M, Mflavonoids, M-saponins, and MS-pa). Each fraction contains various compounds that are detected by PDA-HPLC analysis or by an automatic amino acid analyzer. Three-dimensional HPLC analysis is useful for obtaining the overall-viewing of the many LMC contained in SST and/or its fractions at a glance. Databases containing UV-vis profiles of herbal compounds obtained by RP-HPLC and fingerprint patterns of crude drugs made by 3D HPLC analysis to facilitate identification and qualification of the herbal drugs, are growing. BA, WGG, OAG, BE, WG, OA, LQ, LA, ILQ, ILA, LG (flavonoids), GL, SSb1, SSb2, GSRg1, GSRb1 (triterpene saponins), (6)-gingerol, (6)-shogaol (phenylalkanoids) and arginine (an amino acid) have been detected in these fractions from SST (Table 10). Among them, fifteen compounds (i.e., BA, WGG, BE, WG, LA, LQ, LG, GL, SSb1, SSb2, GSRg1, GSRb1, (6)-gingerol, (6)-shogaol and arginine) have been reported to have various pharmacological effects, which are assumed to be related to the pharmacological effects of SST. The structures of several high molecular polysaccharides with pharmacological activities that were isolated from the constituent herbs of SST (i.e., Bupleurum Radex, Zizyphi Fructus and Ginseng Radix), have been determined (Table 9), although only a few studies on the high molecular bioactive materials in herbs have been reported.

\section{References}

[1] Y. Yamamura, in: E. Hosoya, Y. Yamamura (Eds.), Recent Advances in the Pharmacology of Kampo (Japanese Herbal) Medicines, International Congress Series 854, Excerpta Medica, 1988 , p. 3.

[2] Department of Oriental Medicine, Keio University School of Medicine, What is Kampo? Keio University Medical School, Tokyo (2003). http://web.sc.itc.keio.ac.jp/kampo/english/what_en.html 
[3] M. Yamashiki, A. Nishimura, H. Suzuki, S. Sakaguchi, Y. Kosaka, S. Kakumu, K. Yoshioka, T. Wakita, T. Ishikawa, Hepatology 25 (1997) 1390.

[4] S. Kakumu, K. Yoshioka, T. Wakita, T. Ishikawa, Int. J. Immunopharmacol. 13 (1991) 141.

[5] M. Yamashiki, A. Nishimura, T. Nobori, S. Nakabayashi, T. Takagi, K. Inoue, M. Ito, K. Matsushita, H. Ohtaki, Y. Kosaka, Int. J. Immunopharmacol. 19 (1997) 381.

[6] K. Yoshida, H. Mizukawa, A. Honmura, Y. Uchiyama, H. Kaku, S. Nakajima, E. Haruki, Am. J. Chin. Med. 21 (1993) 171.

[7] N. Satomi, A. Sakurai, F. Iimura, R. Haranaka, K. Haranaka, Biotherapy 2 (1990) 227.

[8] S. Amagaya, H. Higuchi, Y. Ogihara, J. Pharmacobiodyn. 7 (1984) 707.

[9] K. Shimizu, S. Amagaya, Y. Ogihara, J. Pharmacobiodyn. 7 (1984) 891.

[10] M. Kaneko, T. Kawakita, Y. Tauchi, Y. Saito, A. Suzuki, K. Nomoto, Immunopharmacol. Immunotoxicol. 16 (1994) 41.

[11] H. Iwama, S. Amagaya, Y. Ogihara, J. Pharmacobiodyn. 9 (1986) 189.

[12] K. Fujiwara, S. Mochida, S. Nagoshi, O. Iijima, Y. Matsuzaki, S. Takeda, M. Aburada, J. Ethnopharmacol. 46 (1995) 107.

[13] T. Kawakita, A. Yamada, M. Mitsuyama, Y. Kumazawa, K. Nomoto, Immunopharmacol. Immunotoxicol. 9 (1987) 523.

[14] T. Kawakita, S. Nakai, Y. Kumazawa, O. Miura, E. Yumioka, K. Nomoto, A. Yamada, M. Mitsuyama, Int. J. Immunopharmacol. 12 (1990) 515.

[15] Y. Tauchi, A. Yamada, T. Kawakita, Y. Saito, A. Suzuki, Y. Yoshikai, K. Nomoto, Immunopharmacol. Immunotoxicol. 15 (1993) 251.

[16] K. Yonekura, T. Kawakita, M. Mitsuyama, O. Miura, E. Yumioka, A. Suzuki, K. Nomoto, Immunopharmacol. Immunotoxicol. 12 (1990) 647.

[17] Y. Yamaoka, T. Kawakita, M. Kaneko, K. Nomoto, Biol. Pharm. Bull. 18 (1995) 846.

[18] K. Yoshida, H. Mizukawa, A. Honmura, Y. Uchiyama, S. Nakajima, E. Haruki, Am. J. Chin. Med. 22 (1994) 183.

[19] T. Egashira, F. Takayama, Y. Yamanaka, Y. Komatsu, Jpn. J. Pharmacol. 80 (1999) 379.

[20] S. Sakaguchi, E. Tsutsumi, K. Yokota, Biol. Pharm. Bull. 16 (1993) 782.

[21] S. Sakaguchi, E. Tsutsumi, K. Yokota, Biol. Pharm. Bull. 17 (1994) 232.

[22] I. Sakaida, Y. Matsumura, S. Akiyama, K. Hayashi, A. Ishige, K. Okita, J. Hepatol. 28 (1998) 298.

[23] I. Shimizu, Y.R. Ma, Y. Mizobuchi, F. Liu, T. Miura, Y. Nakai, M. Yasuda, M. Shiba, T. Horie, S. Amagaya, N. Kawada, H. Hori, S. Ito, Hepatology 29 (1999) 149.

[24] S. Amagaya, M. Hayakawa, Y. Ogihara, Y. Ohta, K. Fujiwara, H. Oka, H. Oshio, T. Kishi, J. Ethnopharmacol. 25 (1989) 181.

[25] Y. Horie, M. Kajihara, Y. Yamagishi, H. Kimura, H. Tamai, S. Kato, H. Ishii, J. Gastroenterol. Hepatol. 16 (2001) 1260.

[26] M. Miyamura, M. Ono, S. Kyotani, Y. Nishioka, J. Pharm. Pharmacol. 50 (1998) 97.

[27] M. Kusunose, B. Qiu, T. Cui, A. Hamada, S. Yoshioka, M. Ono, M. Miyamura, S. Kyotani, Y. Nishioka, Biol. Pharm. Bull. 25 (2002) 1417.

[28] Y. Ohta, K. Nishida, E. Sasaki, M. Kongo, T. Hayashi, M. Nagata, I. Ishiguro, Am. J. Chin. Med. 25 (1997) 333.

[29] H. Mitsukawa, K. Ikeda, Masui 40 (1991) 794.

[30] M. Kato, W. Liu, H. Yi, N. Asai, A. Hayakawa, K. Kozaki, M. Takahashi, I. Nakashima, J. Invest. Dermatol. 111 (1998) 640.

[31] K. Okita, Q. Li, T. Murakamio, M. Takahashi, Eur. J. Cancer Prev. 2 (1993) 169

[32] H. Yano, A. Mizoguchi, K. Fukuda, M. Haramaki, S. Ogasawara, S. Momosaki, M. Kojiro, Cancer Res. 54 (1994) 448.
[33] H. Ito, K. Shimura, Jpn. J. Pharmacol. 41 (1986) 307.

[34] Y. Kase, M. Yuzurihara, S. Iizuka, A. Ishige, Y. Komatsu, Biol. Pharm. Bull. 20 (1997) 1155.

[35] K. Osanai, K. Takahashi, Kampo Immuno-allergy 4 (1990) 43.

[36] F. Kure, Nippon Igaku Hoshasen Gakkai Zasshi 52 (1992) 96.

[37] G. Piras, M. Makino, M. Baba, Microbiol. Immunol. 41 (1997) 835.

[38] K. Miyamoto, M. Lange, G. McKinley, C. Stavropoulos, S. Moriya, H. Matsumoto, Y. Inada, Am. J. Chin. Med. 24 (1996) 1.

[39] E. Buimovici-Klein, V. Mohan, M. Lange, E. Fenamore, Y. Inada L.Z. Cooper, Antiviral Res. 14 (1990) 279.

[40] Japan's Prescription Herbals for the US Licensed Health Professionals (web site), http://www.honsousa.com/.

[41] N. Okamura, H. Miki, H. Orii, Y. Masaoka, S. Yamashita, H Kobayashi, A. Yagi, J. Pharm. Biomed. Anal. 19 (1999) 603.

[42] I. Saiki, T. Yamaura, Y. Ohnishi, Y. Hayakawa, Y. Komatsu, S Nunome, Chem. Pharm. Bull. (Tokyo) 47 (1999) 1170.

[43] K. Hosoda, Y. Imoto, J. Jobu, M. Noguchi, Yakugaku Zasshi 110 (1990) 755

[44] F.C. Stintzing, J. Conrad, I. Klaiber, U. Beifuss, R. Carle, Phytochemistry 65 (2004) 415.

[45] X. Zhang, H. Xiao, Q. Xu, X. Li, J. Wang, X. Liang, J. Chromatogr. Sci. 41 (2003) 428

[46] A. Akahori, K. Kagawa, A. Shimaoka, J. Jpn. Soc. Oriental Med 27 (1976) 41

[47] H. Tsuji, S. Osaka, H. Kiwada, Chem. Pharm. Bull. (Tokyo) 39 (1991) 1004

[48] A. Shimomura, S. Seo, H. Minato, J. Chem. Soc., Perkin Trans. 1 (1975) 2043.

[49] M. Nose, K. Terawaki, N. Iwahashi, K. Oguri, Y. Ogihara, Biol. Pharm. Bull. 25 (2002) 64.

[50] H. Hayashi, S. Hattori, K. Inoue, O. Khodzhimatov, O. Ashurmetov, M. Ito, G. Honda, Chem. Pharm. Bull. (Tokyo) 51 (2003) 1338.

[51] I.S. Park, E.M. Kang, N. Kim, J. Chromatogr. Sci. 38 (2000) 229

[52] D. Washida, S. Kitanaka, Chem. Pharm. Bull. (Tokyo) 51 (2003) 1314

[53] M. Yoshikawa, S. Hatakeyama, N. Chatani, Y. Nishino, J. Yamahara, Yakugaku Zasshi 113 (1993) 307.

[54] T. Nakanishi, A. Inada, K. Kambayashi, K. Yoneda, Phytochemistry 24 (1985) 339

[55] T. Hatano, H. Ito, T. Yoshida, Phytochemistry 47 (1998) 287.

[56] M. Takido, Taisha (Metab. Dis.) 10 (1973) 261 (in Japanese).

[57] Q. Liu, Y.L. Liu, Yao Xue Xue Bao. 24 (1989) 525.

[58] I. Kitagawa, K. Hori, E. Uchida, W.Z. Chen, M. Yoshikawa, J. Ren, Chem. Pharm. Bull. (Tokyo) 41 (1993) 1567.

[59] M. Takido, M. Aimi, S. Takahashi, S. Yamanouchi, H. Torii, Yakugaku Zasshi 95 (1975) 108.

[60] G.Z. Yang, S. Zhao, Y.C. Li, Yao Xue Xue Bao 37 (2002) 437.

[61] C. Li, M. Homma, K. Oka, Biol. Pharm. Bull. 21 (1998) 1251.

[62] F. Zuo, Z.M. Zhou, M.Z. Yan, M.L. Liu, Y.L. Xiong, Q. Zhang, H.Y. Song, W.H. Ye, Biol. Pharm. Bull. 25 (2002) 558.

[63] N. Ohtake, R. Suzuki, H. Daikuhara, Y. Nakai, M. Yamamoto, S Amagaya, A. Ishige, H. Sasaki, Y. Komatsu, K. Fukuda, S. Hayashi, Int. J. Immunopharmacol. 22 (2000) 419.

[64] J. Kamei, R. Nakamura, H. Ichiki, M. Kubo, Eur. J. Pharmacol. 469 (2003) 159.

[65] M.Y. Lai, S.L. Hsiu, C.C. Chen, Y.C. Hou, P.D. Chao, Biol. Pharm Bull. 26 (2003) 79

[66] Y. Wakui, E. Yanagisawa, E. Ishibashi, Y. Matsuzaki, S. Takeda, H. Sasaki, M. Aburada, T. Oyama, J. Chromatogr. 575 (1992) 131

[67] C.C. Lin, D.E. Shieh, Am. J. Chin. Med. 24 (1996) 31.

[68] T.C. Chou, L.P. Chang, C.Y. Li, C.S. Wong, S.P. Yang, Anesth. Analg. 97 (2003) 1724.

[69] Y. Kimura, N. Matsushita, K. Yokoi-Hayashi, H. Okuda, Planta Med. 67 (2001) 331. 
[70] Y. Kimura, N. Matsushita, H. Okuda, J. Ethnopharmacol. 57 (1997) 63.

[71] I. Wakabayashi, Pharmacol. Toxicol. 84 (1999) 288.

[72] Z. Gao, K. Huang, X. Yang, H. Xu, Biochim. Biophys. Acta 1472 (1999) 643.

[73] S. Ikemoto, K. Sugimura, N. Yoshida, R. Yasumoto, S. Wada, K. Yamamoto, T. Kishimoto, Urology 55 (2000) 951.

[74] F.L. Chan, H.L. Choi, Z.Y. Chen, P.S. Chan, Y. Huang, Cancer Lett. 160 (2000) 219.

[75] Y. Matsuzaki, N. Kurokawa, S. Terai, Y. Matsumura, N. Kobayashi, K. Okita, Jpn. J. Cancer Res. 87 (1996) 170

[76] J.A. Wu, A.S. Attele, L. Zhang, C.S. Yuan, Am. J. Chin. Med. 29 (2001) 69.

[77] Y. Nagaki, S. Hayasaka, C. Kadoi, N. Nakamura, Y. Hayasaka, Jpn. J. Ophthalmol. 45 (2001) 216.

[78] T. Sato, A. Kawamoto, A. Tamura, Y. Tatsumi, T. Fujii, Chem. Pharm. Bull. (Tokyo) 40 (1992) 721.

[79] N. Nakamura, S. Hayasaka, X.Y. Zhang, Y. Nagaki, M. Matsumoto, Y. Hayasaka, K. Terasawa, Exp. Eye Res. 77 (2003) 195.

[80] D.S. Kim, Y.J. Chang, U. Zedk, P. Zhao, Y.Q. Liu, C.R. Yang, Phytochemistry 40 (1995) 1493.

[81] H. Matsuura, R. Kasai, O. Tanaka, Y. Saruwatari, K. Kunihiro, T. Fuwa, Chem. Pharm. Bull. (Tokyo) 32 (1984) 1188.

[82] A. Shimomura, S. Seo, H. Minato, J. Chem. Soc., Perkin. Trans. 1 (1975) 2043.

[83] A. Akahori, K. Kagawa, A. Shimaoka, J. Jpn. Soc. Oriental Med. 24 (1974) 41.

[84] S. Shibata, Yakugaku Zasshi 120 (2000) 849.

[85] A. Olukoga, D. Donaldson, J. R. Soc. Health 120 (2000) 83.

[86] F.C. Stormer, R. Reistad, J. Alexander, Food. Chem. Toxicol. 31 (1993) 303.

[87] Y. Yamamura, J. Kawakami, T. Santa, H. Kotaki, K. Uchino, Y. Sawada, N. Tanaka, T. Iga, J. Pharm. Sci. 81 (1992) 1042.

[88] Y. Nishioka, S. Kyotani, M. Miyamura, M. Kusunose, Chem. Pharm. Bull. (Tokyo) 40 (1992) 1335.

[89] T. Okamoto, K. Kajino, O. Hino, Jpn. J. Pharmacol. 87 (2001) 177.

[90] O.V. Podobed, L.M. Fedorova, O. Abakumova, I.V. Iakusheva, T.A. Tsvetkova, A.V. Gavril'chak, A.B. Shekhter, A.V. Kariakin, Bull. Ep. Biol. Med. 124 (1997) 311.

[91] M. Shinada, M. Azuma, H. Kawai, K. Sazaki, I. Yoshida, T. Yoshida, T. Suzutani, T. Sakuma, Proc. Soc. Exp. Biol. Med. 181 (1986) 205.

[92] R. Pompei, L. Paghi, A. Ingianni, P. Uccheddu, Microbiologica 6 (1983) 247.

[93] B.H. Kroes, C.J. Beukelman, A.J. van den Berg, G.J. Wolbink, H. van Dijk, R.P. Labadie, Immunology 90 (1997) 115.

[94] I.M. Francischetti, R.Q. Monteiro, J.A. Guimaraes, B. Francischetti, Biochem. Biophys. Res. Commun. 235 (1997) 259.

[95] B.N. Rao, M.B. Anderson, J.H. Musser, J.H. Gilbert, M.E. Schaefer, C. Foxall, B.K. Brandley, J. Biol. Chem. 269 (1994) 19663.

[96] F. Zani, M.T. Cuzzoni, M. Daglia, S. Benvenuti, G. Vampa, P. Mazza, Planta Med. 59 (1993) 502.

[97] C.W. Sheu, K.T. Cain, C.J. Rushbrook, T.A. Jorgenson, W.M. Generoso, Environ. Mutagen. 8 (1986) 357.

[98] S. Yano, M. Harada, K. Watanabe, K. Nakamaru, Y. Hatakeyama, S. Shibata, K. Takahashi, T. Mori, K. Hirabayashi, M. Takeda, Chem. Pharm. Bull. (Tokyo) 37 (1989) 2500.

[99] M. Ito, H. Nakashima, M. Baba, R. Pauwels, E. De Clercq, S. Shigeta, N. Yamamoto, Antiviral Res. 7 (1987) 127.

[100] J. Cinatl, B. Morgenstern, G. Bauer, P. Chandra, H. Rabenau, H.W. Doerr, Lancet 361 (2003) 2045.

[101] K. Shimizu, S. Amagaya, Y. Ogihara, J. Pharmacobiodyn. 8 (1985) 718.

[102] H. Abe, M. Sakaguchi, S. Arichi, Nippon Yakurigaku Zasshi 80 (1982) 155.
[103] M. Nose, S. Amagaya, Y. Ogihara, Chem. Pharm. Bull. (Tokyo) 37 (1989) 2736

[104] I. Dobashi, F. Tozawa, N. Horiba, Y. Sakai, K. Sakai, T. Suda, Neurosci. Lett. 197 (1995) 235.

[105] F. Scaglione, F. Ferrara, S. Dugnani, M. Falchi, G. Santoro, F. Fraschini, Drugs Exp. Clin. Res. 16 (1990) 537.

[106] S. Srisurapanon, K. Rungroeng, S. Apibal, P. Cherdrugsi, R. Siripol, V. Vanich-Angkul, C. Timvipark, J. Med. Assoc. Thai. 1 (Suppl. 80) (1997) 81.

[107] B. Kenarova, H. Neychev, C. Hadjiivanova, V.D. Petkov, Jpn. J. Pharmacol. 54 (1990) 447.

[108] M. Liu, J.T. Zhang, Yao Xue Xue Bao 31 (1996) 95.

[109] M. Liu, J.T. Zhang, Yao Xue Xue Bao 30 (1995) 818.

[110] M. Yoshikawa, S. Yamaguchi, K. Kunimi, H. Matsuda, Y. Okuno, J. Yamahara, N. Murakami, Chem. Pharm. Bull. (Tokyo) 42 (1994) 1226.

[111] K.C. Srivastava, T. Mustafa, Med. Hypotheses 39 (1992) 342.

[112] E. Tjendraputra, V.H. Tran, D. Liu-Brennan, B.D. Roufogalis, C.C. Duke, Bioorg. Chem. 29 (2001) 156.

[113] F. Kiuchi, S. Iwakami, M. Shibuya, F. Hanaoka, U. Sankawa, Chem. Pharm. Bull. (Tokyo) 40 (1992) 387.

[114] M. Suekawa, K. Yuasa, M. Isono, H. Sone, Y. Ikeya, I. Sakakibara, M. Aburada, E. Hosoya, Nippon Yakurigaku Zasshi 88 (1986) 263.

[115] J. Yamahara, M. Mochizuki, H.Q. Rong, H. Matsuda, H. Fujimura, J. Ethnopharmacol. 23 (1988) 299.

[116] J. Yamahara, S. Hatakeyama, K. Taniguchi, M. Kawamura, M. Yoshikawa, Yakugaku Zasshi 112 (1992) 645.

[117] M. Hayasaka, G. Kusano, M. Mizugaki, Yakuzaigaku 44 (1989) 33.

[118] S. Higashidate, T. Maekubo, Y. Yamauchi, S. Senda, Jasco. Rep. 20 (1985) 7.

[119] R.H. Boger, S.M. Bode-Boger, Annu. Rev. Pharmacol. Toxicol. 41 (2001) 79.

[120] C. Nieves Jr., B. Langkamp-Henken, Biomed. Pharmacother. 56 (2002) 47.

[121] S. Lazaratos, H. Kashimura, A. Nakahara, H. Fukutomi, T. Osuga, K. Goto, J. Gastroenterol. 30 (1995) 578

[122] M.M. Khattab, M.Z. Gad, D. Abdallah, Pharmacol. Res. 43 (2001) 463.

[123] A. Dembinska-Kiec, D. Pallapies, T. Simmet, B.M. Peskar, B.A. Peskar, Br. J. Pharmacol. 104 (1991) 811.

[124] Y. Yamaoka, T. Kawakita, M. Kaneko, K. Nomoto, Biol. Pharm. Bull. 19 (1996) 936.

[125] Y. Sonoda, T. Kasahara, N. Mukaida, N. Shimizu, M. Tomoda, T. Takeda, Immunopharmacology 38 (1998) 287.

[126] T. Matsumoto, R. Moriguchi, H. Yamada, J. Pharm. Pharmacol. 45 (1993) 535.

[127] T. Matsumoto, J.C. Cyong, H. Kiyohara, H. Matsui, A. Abe, M. Hirano, H. Danbara, H. Yamada, Int. J. Immunopharmacol. 15 (1993) 683.

[128] T. Matsumoto, Y.J. Guo, T. Ikejima, H. Yamada, Immunol. Lett. 89 (2003) 111.

[129] M. Tomoda, K. Takeda, N. Shimizu, R. Gonda, N. Ohara, K. Takada, K. Hirabayashi, Biol. Pharm. Bull. 16 (1993) 22.

[130] H. Yamada, K.S. Ra, H. Kiyohara, J.C. Cyong, H.C. Yang, Y. Otsuka, Phytochemistry 27 (1988) 3163.

[131] H. Yamada, K.S. Ra, H. Kiyohara, J.C. Cyong, Y. Otsuka, Carbohydr. Res. 189 (1989) 209.

[132] Y. Sonoda, T. Kasahara, N. Mukaida, N. Shimizu, M. Tomoda, T. Takeda, Immunopharmacology 38 (1998) 287.

[133] T. Yamamoto, Kampo Immno-allergy 10 (1996) 138 (in Japanese).

[134] M. Maruno, J. Trad. Med. 14 (1997) 81.

[135] Y. Mito, M. Kitaoka, Shimadzu J. 46 (1986) 21.

[136] Y. Nakai, T. Kido, K. Hahimoto, Y. Kase, I. Sakakibara, M. Higuchi, H. Sasaki, J. Ethnopharmacol. 84 (2003) 51. 
[137] H. Yamada, X.B. Sun, T. Matsumoto, K.S. Ra, M. Hirano, H. Kiyohara, Planta Med. 57 (1991) 555.

[138] M. Tomoda, R. Gonda, N. Ohara, N. Shimizu, C. Shishido, Y. Fujiki, Biol. Pharm. Bull. 17 (1994) 859.
[139] R. Gonda, M. Tomoda, N. Shimizu, N. Ohara, H. Takagi, S. Hoshino, Biol. Pharm. Bull. 17 (1994) 1549.

[140] M. Tomoda, K. Hirabayashi, N. Shimizu, R. Gonda, N. Ohara, K. Takada, Biol. Pharm. Bull. 16 (1993) 1087. 